\title{
A catalogação de assunto e a indexação em bibliotecas universitárias: um estudo comparativo com protocolo verbal
}

La catalogación de materias y la indización en bibliotecas universitarias: un estudio comparativo con protocolo verbal

Subject cataloguing and indexing in university libraries: a verbal-protocol comparative study

\author{
Roberta Cristina Dal'Evedove TARTAROTTI y Mariângela Spotti Lopes FUJITA
}

Universidade Estadual Paulista, Av. Hygino Muzzi Filho, 737, Campus Universitário, CEP. 17525900, Marília, SP, Brasil, roberta_tartarotti@yahoo.com.br, mariangelaslf57@gmail.com

\begin{abstract}
Resumen
Se investigan las diferencias en el tratamiento temático de libros y tesis doctorales realizadas por los bibliotecarios en bibliotecas universitarias a través de la indización en la base de datos y de la catalogación de materias en el catálogo colectivo en línea. Mediante la metodología cualitativa de recogida de datos denominada Protocolo Verbal Individual (PVI), se estudiaron cinco sujetos (2 catalogadores, 2 indizadores y 1 catalogador-indizador) en tres bibliotecas universitarias públicas de la Universidad de São Paulo, Brasil. Se constata que los profesionales realizan la catalogación de materias y la indización de tesis de manera distinta, ya que en las bases de datos el proceso de indización se realiza a un nivel más alto de especificidad que la catalogación de materias en el catálogo colectivo en línea. Parece que esta actitud diferencial de los profesionales está directamente relacionada con la concepción del análisis documental que adquirieron durante su formación universitaria y con la política de indización del sistema donde actúan, especialmente con los diferentes vocabularios controlados utilizados en los sistemas de recuperación de la información.
\end{abstract}

Palabras clave: Indización. Catalogación de materias. Protocolo verbal individual. Catálogos colectivos en línea. Bases de datos. Tesis doctorales. Bibliotecas universitarias. Brasil.

\section{Introdução}

No âmbito da Ciência da Informação, a área de Organização e Representação do Conhecimento dispõe do arcabouço teórico-prático necessário no que tange à produção, tratamento e recuperação da informação/conhecimento na sociedade, tendo o tratamento da informação como elo complementar entre a produção e o uso de informações. Embora presente em outras unidades de informação como arquivos e museus, a abordagem teórica da catalogação de assunto, conforme Fujita, Rubi e Boccato (2009, p. 39) está essencialmente ligada à construção de catálogos

\begin{abstract}
The differences in the subject cataloguing and indexing of books and doctoral theses carried out by university librarians were analyzed. Using the qualitative data collection methodology called Individual Verbal Protocol $(\mathrm{PVI})$, five subjects (2 catalogers, 2 indexers and 1 cataloger-indexer) were studied from three public university libraries of the University of São Paulo, Brazil. It was verified that the professionals perform the indexing of theses in the databases at a higher level of specificity than the cataloging of library materials for the online catalog. It seems that this differential attitude of the professionals is directly related to the conception of document analysis that they acquired during their university education and to the indexing policy of the system where they act, specially with the different controlled vocabularies used in the information retrieval systems.
\end{abstract}

Keywords: Indexing. Subject cataloguing. Verbal Protocol. Online public catalogues. Databases. University libraries. Doctoral thesis. Brazil.

de bibliotecas, enquanto que a indexação está ligada à construção de índices de bibliografias em serviços de informação bibliográficos que produzem bases de dados. Ainda para as autoras, a atuação dos catálogos como verdadeiras bases de dados é uma tendência devido a dois principais fatores:

a dimensão que a internet deu aos catálogos das bibliotecas, uma vez que agora eles estão disponíveis sem fronteiras espaciais e temporais, permitindo ao usuário acessá-los de qualquer lugar a qualquer hora; e a exigência cada vez maior do usuário em aspirar a que os catálogos atuem como verdadeiras bases de dados, oferecendo especificidade, rapidez e hiperlinks a textos completos. 
Como responsáveis pelo armazenamento, localização, busca e seleção, sob demanda, de dados pertinentes a um determinado assunto, os catálogos coletivos online e as bases de dados de bibliotecas universitárias são considerados sistemas de recuperação da informação. Contudo, se a qualidade da catalogação de assunto e da indexação inexistir no tratamento/organização documental, consequentemente se refletirá na qualidade dos próprios produtos. Desta forma, nestes sistemas de recuperação da informação a qualidade da representação temática está diretamente relacionada à qualidade da análise temática, considerando sua complexidade inerente ao fazer profissional.

Partindo-se da relevância de investigações teórico-metodológicas em torno do profissional que realiza a análise de assunto, visando contribuir para a otimização do tratamento temático da informação em contexto de bibliotecas universitárias, o objetivo do artigo é investigar a atuação bibliotecária no tratamento temático da informação de bibliotecas universitárias, por meio da indexação em base de dados e da catalogação de assunto em catálogo coletivo online, utilizandose como metodologia qualitativa de coleta de dados a técnica introspectiva do Protocolo Verbal (PV) sistematizada por Ericsson e Simon (1993), na modalidade Protocolo Verbal Individual (PVI).

\section{Os processos de catalogação de assunto e de indexação em bibliotecas universitárias}

As bibliotecas universitárias foram uma das primeiras instituições em prover o uso de sistemas de recuperação da informação, em duas principais frentes: provendo acesso tanto para os catálogos da própria biblioteca como para bases de dados comerciais. Na contemporaneidade, diversos fatores contribuíram para a utilização dos sistemas de recuperação da informação em bibliotecas universitárias de forma mais efetiva.

Os catálogos coletivos online e as bases de dados de bibliotecas universitárias são sistemas de recuperação da informação fundamentais, na medida em que possuem âmbito informacional definido, informação especializada e fornecimento de produtos informacionais específicos.

O catálogo é um produto da catalogação, atividade de natureza descritiva da área de tratamento da informação. Como um sistema de recuperação da informação, tanto a catalogação (processo), como o catálogo (produto) permitem a mediação entre documentos e usuários. Por realizarem um processo de comunicação, são determinados historicamente de acordo com o contexto em que estão inseridos.
A catalogação de assunto é a dimensão do processo de catalogação responsável pela análise de assunto de itens informacionais, bem como o fornecimento de notações de classificação e cabeçalhos de assunto que representem o assunto dos documentos. É definida como "representação, nos catálogos de biblioteca, dos assuntos contidos no acervo" (Fiuza, 1985, p. 257) e uma operação intelectual do exame do documento para extração e representação de assuntos nele contidos, que servem de ponto de acesso para busca e recuperação do documento original no acervo, bem como para agrupamento das obras por área de abrangência temática dos documentos relacionados entre si (Shoham y Kedar, 2001).

Por outro lado, as bases de dados são um conjunto de dados estruturados de forma sistemática, geralmente específicos sobre algum campo do conhecimento. Atualmente, as bases de dados em bibliotecas universitárias promovem a divulgação e comunicação de informações especializadas e criação de conhecimento, visto seu papel em fornecer informação atualizada, precisa e confiável, de acordo com a demanda dos usuários (Tartarotti, 2014, p. 112).

No processo de atribuição de assuntos em bases de dados ou indexação, os assuntos utilizados para descrever os documentos dependem de cada área científica especializada. Estes assuntos podem ser descritos por meio de informações localizadas em determinadas partes do documento, como título, resumo ou em um vocabulário controlado. A maioria das bases de dados utilizam termos de indexação em um campo descritor, geralmente oriundos de um tesauro específico, ou seja, um vocabulário de indexação formalmente estruturado (Rasmussen, 2011, p. 699).

Conceitualmente, a indexação é um processo formado por subprocessos ou etapas que tem como objetivo identificar o conteúdo de um documento, por meio de uma metalinguagem construída - a linguagem documental - com o intuito de promover a efetiva recuperação da informação (Tartarotti, 2014, p. 21). Suas principais etapas são leitura documental, análise de assunto/identificação de conceitos, seleção de conceitos e tradução de conceitos.

Sintetizadas por Gil Leiva (2008, p. 62), as diferentes abordagens na prática da indexação de documentos por indexadores podem ser reunidas em quatro vertentes presentes na literatura: indexação orientada para o documento, indexação orientada para o conteúdo, indexação orientada para o usuário e indexação orientada para o 
domínio, sendo esta última considerada a concepção ideal, ao considerar outros elementos além do documento ou o usuário.

O objetivo da prática profissional tanto do indexador como do catalogador de assunto é tornar conhecido o assunto de um documento, ou seja, representar seu conteúdo por meio de conceitos significativos. Mesmo considerados como processos de tratamento temático da informação distintos, a qualidade da indexação e da catalogação de assunto está relacionada à capacidade de reconstruir o assunto tratado em um documento em conceitos para recuperação posterior pelo usuário do sistema de informação.

\section{Procedimentos metodológicos}

No intuito de realizar a coleta de dados com os catalogadores com a técnica introspectiva do PVI para observação comparativa do processo de análise de assunto na catalogação de assunto e na indexação de teses na área de Saúde, elaborou-se o plano metodológico da pesquisa.

O universo de pesquisa constitui-se de três bibliotecas universitárias públicas da Universidade de São Paulo: Biblioteca da Faculdade de Odontologia (FO), Biblioteca da Faculdade de Saúde Pública (FSP) e Biblioteca do Instituto de Psicologia (IP). A amostra foi definida após pesquisa nos sistemas de recuperação da informação e contato com as bibliotecas participantes, verificando-se que realizam, com as mesmas teses, tanto a catalogação de assunto no catálogo coletivo online DEDALUS(1) do Sistema de Bibliotecas da Universidade de São Paulo quanto a indexação na base de dados Literatura Latinoamericana e do Caribe em Ciências da Saúde (LILACS) (2).

Cabe esclarecer que, inicialmente, a proposta da pesquisa seria realizar um estudo comparativo no contexto do Conselho de Reitores das Universidades Estaduais Paulistas (CRUESP) (3), ou seja, tendo como universo de pesquisa uma biblioteca da USP, uma biblioteca da UNESP e uma biblioteca da UNICAMP com o documento tipo livro. Entretanto, verificou-se que nenhuma biblioteca da UNICAMP realiza a indexação de livros na LILACS, justificando-se, assim, a escoIha de teses para este estudo.

No tocante à infraestrutura material para a realização da aplicação do PVI, as bibliotecas atenderam os quesitos necessários. Para tanto, foi utilizado o próprio ambiente de trabalho do bibliotecário catalogador e indexador, ou seja, com os sujeitos em situação natural, para que assim a coleta de dados pudesse refletir a realidade das atividades de catalogação e indexação.
Salienta-se que as bibliotecas possuíam ambientes adequados para a aplicação do PVI, pois as atividades a serem investigadas (catalogação e indexação) fazem parte da rotina dos bibliotecários que nelas atuam. A coleta de dados foi realizada uma única vez em cada Biblioteca universitária, gerando 6 protocolos verbais, com 5 sujeitos participantes. No caso da Biblioteca da Faculdade de Saúde Pública (FSP), considerando-se que o mesmo profissional realiza tanto a catalogação de assunto no DEDALUS quanto a indexação de teses na LILACS, foram aplicados dois (2) protocolos com o mesmo bibliotecário. A aplicação do PVI pautou-se nos seguintes procedimentos metodológicos (adaptados de Nardi, 1999).

\subsection{Procedimentos anteriores à aplicação do PVI}

Definição do universo da pesquisa: Após verificação de quais bibliotecas realizavam tanto a catalogação de assunto em catálogo coletivo online como a indexação em base de dados, as bibliotecas universitárias foram selecionadas.

Seleção dos sujeitos: A aplicação da técnica do PVI ocorreu com 5 bibliotecários que atuam no tratamento temático da informação, mais especificamente nas atividades de catalogação de assunto e indexação das bibliotecas supracitadas. As coletas propiciaram a geração de 6 protocolos verbais. Ressalta-se a discrepância entre os números apresentados, considerando-se que em uma das bibliotecas pesquisadas, o mesmo profissional realizou tanto a catalogação de assunto como a indexação de tese.

Definição da tarefa: Realizar a catalogação de assunto/indexação de uma tese no DEDALUS e da mesma tese na LILACS, sendo 1 em cada biblioteca, para observação por meio da técnica do $\mathrm{PVI}$, que consiste na gravação de voz, enquanto o profissional realiza a atividade proposta.

Seleção do texto-base: O material selecionado para o tratamento temático da informação foram três (3) teses de doutorado pertencentes à área científica especializada das bibliotecas pesquisadas:

Gomes, N. F. (2010). A conduta moral na administração pública: um estudo com ocupantes de cargos comissionados. // 202 f. Tese (Doutorado em Psicologia) - Instituto de Psicologia, Universidade de São Paulo.

Silva, B. M. H. (2010). Efeito do tratamento térmico sobre a sorção e solubilidade, tenacidade à fratura e grau de conversão de compósitos restauradores diretos. // $88 \mathrm{f}$. Tese (Doutorado em Ciências Odontológicas) - Faculdade de Odontologia, Universidade de São Paulo.

Bocchiglieri, M. M. (2010). O lixiviado dos aterros sanitários em estações de tratamento dos sistemas públicos de esgotos. // 257 f. Tese (Doutorado em Saúde Pública) Faculdade de Saúde Pública, Universidade de São Paulo. 
Conversa informal com os sujeitos: Realizou-se uma conversa informal com a direção e com os sujeitos catalogadores e indexadores de cada biblioteca universitária por telefone e e-mail, resultando na aceitação e definição das datas para a realização da coleta de dados. Antes da aplicação do PVI, foram mencionados os objetivos da pesquisa e a importância da mesma para o desenvolvimento da área de tratamento temático da informação em bibliotecas universitárias. Foi entregue para cada sujeito o Termo de Consentimento Livre e Esclarecido (TCLE), assinado tanto pela pesquisadora como pela orientadora. Solicitou-se aos sujeitos a assinatura do documento e aceitação formal da participação na pesquisa, ficando uma cópia para os sujeitos. Ressaltou-se, ainda, que a identidade de cada um dos sujeitos permaneceria oculta, com o propósito de não comprometer os dados e deixá-los à vontade durante a realização da tarefa de modo mais natural possível, seguindo sua rotina diária de atividade.

Familiarização dos sujeitos com a técnica do PVI: Os sujeitos participantes foram apresentados à técnica introspectiva do PVI e seus respectivos procedimentos, sendo-lhes instruídos no modo como deveriam proceder durante a aplicação da mesma. Foi esclarecido que é preciso "pensar alto" durante a leitura e exteriorizar seus processos mentais, procurando esquecer a presença da pesquisadora que esteve presente apenas com o intuito de lembrar que é preciso "pensar alto" e controlar o gravador.

\subsection{Procedimentos durante a aplicação do PVI}

Gravação do "pensar alto" dos sujeitos participantes: Foi realizada a gravação do "pensar alto" dos bibliotecários durante a catalogação de tese no catálogo coletivo online e a indexação na base de dados, por meio de um gravador digital. A conversa informal, familiarização com a tarefa, instruções aos sujeitos e a aplicação do PVI foram aplicadas individualmente com cada profissional, respeitando sua própria individualidade e necessidades.

\subsection{Procedimentos após a aplicação do PVI}

Transcrição literal das gravações das falas dos sujeitos participantes: Foram realizadas as transcrições literais das falas dos sujeitos participantes, preservando a identidade dos mesmos por meio de siglas específicas de acordo com a atividade realizada - indexador/catalogador de assunto, sendo que para as transcrições utilizou-se como apoio o software Express Scribe Transcription. No intuito de obter uma melhor visualização dos processos adotados pelos sujeitos, nas transcrições foram utilizadas notações específicas (adaptadas de Cavalcanti, 1989), por exemplo, as apresentadas no Quadro 1:

\begin{tabular}{|c|c|}
\hline Notação & Significado \\
\hline$\ldots$ & pausas curtas \\
\hline$\ldots \sim \sim$ & pausas longas \\
\hline$((\mathrm{RM}))$ & tom de ironia do sujeito \\
\hline$((\mathrm{RI}))$ & riso do sujeito \\
\hline$((\mathrm{FR}))$ & vocalização e riso ao mesmo tempo do sujeito \\
\hline$[\ldots]$ & trecho do texto-base vocalizado pelo sujeito \\
\hline$<>$ & termos identificados pelo sujeito \\
\hline$(<>)$ & $\begin{array}{l}\text { termos finais atribuídos ao documento pelo } \\
\text { sujeito }\end{array}$ \\
\hline$(->)$ & $\begin{array}{l}\text { trecho do texto-base "saltado" (ignorado) } \\
\text { na leitura }\end{array}$ \\
\hline “..." & $\begin{array}{l}\text { trecho de instruções do sistema } \\
\text { de recuperação da informação }\end{array}$ \\
\hline\{\} & $\begin{array}{l}\text { trecho de material de apoio (obra de } \\
\text { referência) utilizado para compreensão } \\
\text { do conteúdo documental pelo sujeito ou } \\
\text { definição do termo no sistema de recuperação } \\
\text { da informação }\end{array}$ \\
\hline$(\ldots)$ & $\begin{array}{l}\text { omissão de trecho não relevante } \\
\text { na transcrição }\end{array}$ \\
\hline
\end{tabular}

Quadro I. Notações específicas para as transcrições

Leitura detalhada dos dados em busca de fenômenos significativos e recorrentes para elaboração de categorias de análise: Posteriormente, foi realizada leitura detalhada das transcrições com o intuito de buscar fenômenos significativos para a construção das categorias de análise dos dados.

Construção das categorias de análise: Após leitura detalhada dos dados, foram construídas as unidades de análise, eixos temáticos e categorias de análise baseadas tanto na literatura como na prática profissional, por meio das quais as informações obtidas pela aplicação do PVI foram estruturadas.

Retorno aos dados para retirar trechos da discussão que exemplifiquem cada categoria de análise: Realizou-se a releitura das transcrições visando à retirada de trechos da discussão que melhor exemplificassem cada categoria de análise, mediante a elaboração de quadros e síntese dos principais aspectos observados.

\section{Resultados e discussão}

Para atender aos objetivos da pesquisa, com os dados coletados dos protocolos verbais individu- 
ais foi realizada a transcrição integral dos mesmos, em busca de fenômenos significativos como subsídios à elaboração de categorias de análise, pautadas tanto nos aportes teóricos como nas declarações realizadas pelos sujeitos participantes. Por sua vez, cada eixo temático com suas respectivas categorias de análise é apresentado em quadros, com o intuito de evidenciar trechos das declarações dos sujeitos participantes durante a realização da catalogação de assunto e indexação por meio da abordagem qualitativa do PVI. Salienta-se que cada trecho foi identificado por meio das seguintes siglas (Quadro II).

\begin{tabular}{|c|c|}
\hline Profissional & Sigla \\
\hline Catalogador da Faculdade de Odontologia & $(\mathrm{C}-\mathrm{FO})$ \\
\hline Indexador da Faculdade de Odontologia & $(\mathrm{I}-\mathrm{FO})$ \\
\hline $\begin{array}{l}\text { Catalogador da Biblioteca da Faculdade de } \\
\text { Saúde Pública }\end{array}$ & (C-FSP) \\
\hline $\begin{array}{l}\text { Indexador da Biblioteca da Faculdade de Saúde } \\
\text { Pública }\end{array}$ & $(\mathrm{I}-\mathrm{FSP})$ \\
\hline $\begin{array}{l}\text { Catalogador da Biblioteca do Instituto de } \\
\text { Psicologia }\end{array}$ & $(\mathrm{C}-\mathrm{IP})$ \\
\hline Indexador da Biblioteca do Instituto de Psicologia & $(\mathrm{I}-\mathrm{IP})$ \\
\hline
\end{tabular}

Quadro II. Siglas dos sujeitos participantes das bibliotecas pesquisadas utilizadas nas transcrições

Desse modo, são apresentadas a seguir as unidades de análise, os eixos temáticos e as categorias de análise elaboradas como subsídios para a análise qualitativa (Quadro III).

\subsection{Aspectos relacionados ao processo documental}

\subsubsection{Eixo temático: Tratamento descritivo da informação para catalogação (catálogo coletivo online)}

Manual de catalogação descritiva: O catalogador da FO pautou-se tanto em um manual elaborado pelo próprio bibliotecário como na ajuda de campo do software ALEPH do DEDALUS, que apresenta ainda exemplos para a catalogação descritiva de forma padronizada no SIBiUSP.

e tudo o que eu for catalogar eu tenho que seguir isso aqui ó ... "Orientações de Catalogação", tá vendo? (...) Então eu vou ter que preencher campo a campo ... todos os dados (C-FO)

Os catalogadores da FSP e do IP também utilizaram a ajuda de campo do sistema. Além disso, para cada tipo de material é apresentada uma planilha default com os campos de preenchimento obrigatório e ao enviar o registro para o sistema, caso tenha alguma inconsistência, o mesmo acusa, facilitando a atividade.

\begin{tabular}{|c|c|c|}
\hline $\begin{array}{l}\text { Unidade } \\
\text { de análise }\end{array}$ & $\begin{array}{l}\text { Eixos } \\
\text { temáticos }\end{array}$ & $\begin{array}{l}\text { Categorias } \\
\text { de análise }\end{array}$ \\
\hline \multirow{4}{*}{$\begin{array}{l}\text { Aspectos } \\
\text { relacionados } \\
\text { ao processo } \\
\text { documental }\end{array}$} & $\begin{array}{l}\text { Tratamento } \\
\text { descritivo } \\
\text { da informação } \\
\text { para catalogação } \\
\text { (catálogo coletivo } \\
\text { online) }\end{array}$ & $\begin{array}{l}\text { - Manual de catalogação } \\
\text { descritiva }\end{array}$ \\
\hline & $\begin{array}{l}\text { Tratamento } \\
\text { descritivo } \\
\text { da informação } \\
\text { para indexação } \\
\text { (base de dados) }\end{array}$ & $\begin{array}{l}\text { - Manual de descrição } \\
\text { documental }\end{array}$ \\
\hline & $\begin{array}{l}\text { Tratamento } \\
\text { temático } \\
\text { da informação } \\
\text { (catalogação de } \\
\text { assunto/indexação) }\end{array}$ & $\begin{array}{l}\text { - Análise de assunto/ } \\
\text { identificação de conceitos } \\
\text { · Seleção de conceitos } \\
\text { · Representação/ } \\
\text { tradução de conceitos }\end{array}$ \\
\hline & $\begin{array}{l}\text { Linguagem } \\
\text { documental }\end{array}$ & $\begin{array}{l}\text { - Adequação/atualização } \\
\text { da linguagem documental } \\
\text { para catalogação de } \\
\text { assunto/indexação } \\
\text { · Desempenho da } \\
\text { linguagem documental } \\
\text { para catalogação de } \\
\text { assunto/indexação } \\
\text { · Pertinência da } \\
\text { linguagem documental } \\
\text { com a linguagem da } \\
\text { comunidade usuária }\end{array}$ \\
\hline $\begin{array}{l}\text { Aspectos } \\
\text { relacionados } \\
\text { ao catalogador } \\
\text { de assunto/ } \\
\text { indexador }\end{array}$ & $\begin{array}{l}\text { Atuação } \\
\text { profissional } \\
\text { do catalogador/ } \\
\text { indexador }\end{array}$ & $\begin{array}{l}\text { · Concepção sobre } \\
\text { catalogação de assunto } \\
\text { · Concepção sobre } \\
\text { indexação } \\
\text { · Fatores interferentes } \\
\text { · Formação do } \\
\text { catalogador de assunto } \\
\text { · Formação do indexador }\end{array}$ \\
\hline \multirow{2}{*}{$\begin{array}{l}\text { Aspectos } \\
\text { relacionados } \\
\text { ao contexto } \\
\text { de bibliotecas } \\
\text { universitárias }\end{array}$} & $\begin{array}{l}\text { Política de } \\
\text { tratamento temático } \\
\text { da informação } \\
\text { documental }\end{array}$ & $\begin{array}{l}\text { - Manual de catalogação } \\
\text { de assunto } \\
\text { - Manual de indexação } \\
\text { - Nível de especificidade/ } \\
\text { exaustividade } \\
\text { - Quantidade de termos }\end{array}$ \\
\hline & $\begin{array}{l}\text { O usuário } \\
\text { do sistema } \\
\text { de recuperação } \\
\text { da informação }\end{array}$ & $\begin{array}{l}\text { - Recuperação por } \\
\text { assunto em catálogo } \\
\text { coletivo online e em bases } \\
\text { de dados na biblioteca } \\
\text { - Preocupação com a } \\
\text { perspectiva do usuário }\end{array}$ \\
\hline
\end{tabular}

Quadro III. Elaboração das categorias e subcategorias de análise a partir dos referenciais teóricos apresentados nas seções anteriores e dos objetivos da pesquisa

\subsubsection{Eixo temático: Tratamento descritivo da informação para indexação (base de dados)}

\section{Manual de descrição documental}

\footnotetext{
Quando surge alguma, às vezes na hora que você tá preenchendo surge umas dúvidas, tal, então você tem no próprio aplicativo você tem como você buscar a informação ... pra te ajudar, uma informação auxiliar ... tá? (I-FO)
} universitárias: um estudo comparativo com protocolo verbal. // Scire. 23:1 (en.-jun. 2017) 57-66. ISSN 1135-3716. 
O indexador da FO pautou-se na ajuda de campo do software LILDBI-Web da Metodologia LILACS para descrição documental, o que denominou de "informação auxiliar ou assistente". Este manual, denominado de Manual de Descrição Bibliográfica orienta o preenchimento dos campos de dados definidos no formato LILACS, descreve cada campo de dados e apresenta exemplos de preenchimento. A padronização de alguns elementos segue a AACR2 (Código de Catalogação Anglo-Americano) e a ISO (International Standard Organization), possibilitando o controle de qualidade e cooperação no tratamento das informações bibliográficas. O profissional ressalta ser positivo o fato de o sistema acusar alguma inconsistência por meio de alertas coloridos.

O indexador da FSP também utilizou o assistente para realizar a descrição documental da tese, inclusive explicitando durante o protocolo algumas instruções, sanando suas dúvidas. O indexador do IP compara a descrição documental da LILACS com a catalogação do MARC no DEDALUS, pois os campos obrigatórios na planilha default na LILACS aparecem em destaque, na cor vermelha, proporcionando uma descrição mais rápida, enquanto que no DEDALUS isso não ocorre. Além disso, sugere que o campo de preenchimento do Currículo Lattes do autor da tese, implantado mais recentemente, também possa ser validado pelo sistema.

\subsubsection{Eixo temático: Tratamento temático da informação (catalogação de assunto/indexação)}

\section{Análise de assunto/identificação de conceitos}

O que que a gente costuma fazer, a gente vai, eu já abro quando pega a tese, já vou e já abro direto no ... no resumo ... certo? Aí eu dou uma ... dou uma lida assim, né? Dou uma lida no resumo, tal. É ... tento ver também com relação ao título né e no resumo (...) Como às vezes é ... muito, eu tento dentro do texto já no olhar clínico já tento tirar algumas palavras ... né? Algumas palavras, isso dentro de uma experiência já adquirida de indexação então eu já vou direto e já olho, já vejo aqui se é possível tirar algumas palavras ... aí ... olhei né, aí o que que eu faço? Olho na ficha catalográfica que tem também a ... já tem aqui a indexação. (I-FO)

Deixa eu olhar nas palavras-chave <Estações de tratamento>, <Sistemas públicos de esgoto> ... Tô abrindo no SIBIX (...) enquanto isso eu vou aqui pro resumo da tese ... (...) vou começar indexando pelos termos principais que aparecem no título depois eu vou pro objetivo ... no resumo ... aqui (C-FSP)

Todos os profissionais, sejam catalogadores de assunto ou indexadores, realizaram a análise do conteúdo do documento, entretanto, em diferentes níveis de profundidade. A leitura documental é considerada como a fase mais importante do processo de análise de documentos, sendo o sucesso nesta fase inicial que garantirá o restante do processo.

\section{Seleção de conceitos}

Estes foram os termos que ficaram. São cinco termos que foram dados pra essa tese e eu vou agora (...) voltar no formulário da catalogação pra acrescentar mais campos aqui, só tenho um. ... Então eu vou criar mais campos que faltam pra eu colocar todos os assuntos (C-IP)

\section{Representação/tradução de conceitos}

É ... < Tenacidade>. Tenho aqui o descritor exato (...) palavra ou termo. Então eu vou colocar <Tenacidade>. <Tenacidade> não tem. Volta ... vou pra palavra. Também não. Então... sem chance. Daí, bom, eu tento... buscar alguma ... tento esmiuçar o máximo que eu posso, mas (...) Aí eu vou lá e coloco as palavras do autor, porque aí é o autor que tá colocando ... <Tenacidade à fratura $>$, vamos ver aqui, <Grau de conversão> ... <Grau de conversão >, também não ... Termo exato também não, acho que não vai ter ... bom... não consegui ir mais ... dentro do que tá aqui (I-FO)

então é só transportar do vocabulário pro formulário de catalogação do DEDALUS ... essa parte da indexação então ... já tá ... pronta. (...) Bom, então essa tese ficou com os termos (<Ética $>)$... (<Moral $>)$... (<Trabalho>), (<Administração pública $>$ ) e (<Teoria crítica $>$ ). (C-IP)

< Individualização> tem no DeCS, mas < Individualização - Psicologia> não tem. (...) ... Mas eu ficaria numa dúvida aqui, colocar ou não. Na dúvida ... regra ... geral que a gente dá ... embora tem que ter ... pelo menos $50,70 \%$ de certeza. ((FR)) (...) Por exemplo, aqui <Psicologia do indivíduo> é um ... termo que tá parecendo aqui é um campo totalmente ... que vai em outra linha ... não é ... esse eu não usaria ... <Formação do indivíduo> ... tá aqui ó. ... Você tá vendo como a nossa terminologia tão específica que é né? (...) Aqui já foram quatro termos hein? O que eu faço também é depois dar uma olhadinha, pelo menos na parte em português e já ... reavaliar se eu não to colocando um muito geral ou um concorrente que não necessitaria ... (I-IP)

O catalogador da FO explicita que o SIBIX não alcança o nível de especificidade abordado na tese. Desse modo, termos que poderiam ser atribuídos ao documento não puderam ser utilizados devido à restrição do vocabulário controlado utilizado na etapa de representação e tradução de conceitos. Entretanto, a mesma situação ocorre com o indexador da mesma instituição, pois ao tentar traduzir na linguagem de indexação termos identificados e selecionados durante a análise de assunto, percebe que no DeCS os termos não são localizados.

O catalogador da FSP denota que não será utilizada, na etapa de tradução, a mesma quantidade 
de termos identificados e selecionados. O catalogador do IP, ao analisar a ficha catalográfica da tese, expõe que, pela sua experiência profissional, é possível verificar se os termos ali contidos fazem ou não parte do vocabulário controlado, ou seja, do SIBIX. O indexador do IP, ao mesmo tempo em que identifica e seleciona os conceitos significativos do conteúdo da tese, também realiza a pesquisa dos descritores no vocabulário controlado específico da área de Psicologia. $O$ vocabulário controlado também auxilia o profissional na compreensão do conteúdo do documento.

Fujita, Rubi e Boccato (2009, p. 24) explicam que durante o processo de indexação, as etapas não precisam ser, necessariamente, realizadas de maneira sequencial, visto que o indexador profissional já familiarizado com o processo pode realizálas simultaneamente. Do mesmo modo, quanto mais familiarizado com a área científica especializada no qual atua, mais estas etapas são superpostas durante os processos de catalogação de assunto/indexação em bibliotecas universitárias.

\subsubsection{Eixo temático: Linguagem documental}

Adequação/atualização da linguagem documental para catalogação de assunto/indexação

aí as palavras-chaves é do autor, e tá aqui, posso colocar só, mas aí o que que acontece? É ... como eu faço a indexação pelo DeCS ... que é um aplicativo da BIREME ... tá? Daí ele tem a palavra-chave, tal. Então geralmente eu uso isso aí só depois se caso eu não conseguir nada pelo DeCS aí eu coloco esse aqui ... coloco as palavras-chave do autor. (IFO)

palavra-chave do autor ... esse a gente tá usando ainda, que já é justamente aqueles termos não ... inclusos (...) ... então eu coloco aqui e coloco em um arquivo word depois e trimestralmente eu passo pra (...) ... porque eu não posso pré-julgar e dizer que aquele termo ... que o autor colocou pra tese dele ... não estando no DeCS, não estando na ... terminologia nossa ... não seja válido. Eu não posso préjulgar, dizer não, esse termo não se aplica ... Aí vem em seguida os nossos termos ... né? ... Então eu venho aqui na terminologia ... aí que começa a brincadeira da indexação. (I-IP)

O catalogador da FO explica que quando o registro da tese é carregado no ALEPH (oriundo da Biblioteca Digital), no campo 950 (termo livre) são carregados os assuntos atribuídos pelo autor da tese (palavras-chave do autor quando da elaboração de sua ficha catalográfica).

Este mesmo campo é utilizado pelo catalogador para inserir termos que julga relevantes para a recuperação da tese, mas cujo vocabulário controlado (VocaUSP) não contempla. Ressalta a importância de acréscimo destes termos em lin- guagem natural no campo livre, para futura análise de sua inserção ou elaboração de remissivas no vocabulário controlado. O indexador da FO salienta que, caso as palavras-chave não sejam contempladas na linguagem controlada da LILACS - O DeCS, as mesmas são utilizadas no campo "palavras-chave do autor" no registro do documento. Além disso, compara o DeCS com o SIBIX, considerando que neste último, devido às atualizações, é mais provável encontrar termos para a tradução na indexação.

O indexador do IP também se vale do mesmo campo para inserir os termos potenciais que poderiam fazer parte da terminologia em Psicologia. Desse modo, o bibliotecário que atua no tratamento temático da informação desempenha um importante papel ao realizar o levantamento dos termos relevantes/pertinentes que representem o conteúdo do documento e que possam ser buscados pelos usuários do sistema de recuperação da informação, mas que não fazem parte da linguagem documental, ou seja, do vocabulário controlado utilizado pela instituição. É importante destacar que tanto o catálogo coletivo online como a base de dados utilizam os vocabulários controlados, VocaUSP para a catalogação de assunto e DeCS para a indexação, embora em diferentes níveis de especificidade e abrangência.

\subsection{Aspectos relacionados ao indexador}

\subsubsection{Eixo temático: Atuação profissional do catalogador/indexador}

\section{Concepção sobre indexação}

É lógico, como diz o ... o Lancaster qualquer indexação por, melhor que ... mais racional que ela tem que ser ela é ... subjetiva ... e ... no caso das outras ... é ... Unidades ... às vezes ... o ... o profissional bibliotecário deixa passar né? ... Termos ... que é o próximo que eu vou colocar é ... <Percepção do sujeito> (I-IP)

Somente o IP explicita sua concepção sobre indexação, pois percebe a subjetividade do processo de indexação e a relevância do profissional em selecionar termos que representam o conteúdo do documento.

\section{Formação do indexador}

Uma coisa que facilita em termos de indexação lá na frente, até pro professor a gente sabe a linha ... teórica que ele escreve ... no caso eu como são mais de 80 professores aqui da Escola eu busco ainda ... entender ... por mais que ... eu tenha experiência nunca é ... o pensamento nunca para ... tem que se atualizar (I-IP)

Somente o indexador do IP aponta a necessidade de atualização profissional, visto a complexidade 
inerente à área científica especializada, considerando-se que o profissional em geral não é um especialista na área em que atua. De acordo com Guinchat e Menou (1994, p. 497), “a formação contínua é indispensável em uma profissão em que as técnicas e os conhecimentos evoluem rapidamente e na qual a demanda e as novas necessidades estão em crescimento contínuo".

\subsection{Aspectos relacionados ao contexto}

\subsubsection{Eixo temático: Política de tratamento temático da informação documental}

\section{Nível de especificidade/exaustividade}

Então ele tá sempre falando dessa ... as <Propriedades> desse <Material> ... Aí ele fala muito olha, ele fala de alguns termos ... que ele não vai ter, eu não tenho esse tal de <Calorimetria> também aqui, então tem termos que eu mais ou menos que eu já sei que não vou achar ... é muito específico ... esse banco, ele não ... ah, métodos ... ele não tem termos tão específicos (C-FO)

O catalogador da FO salienta que os termos da tese são muito específicos, e pela sua experiência profissional não poderão ser inseridos no campo 650 como assuntos, pois o vocabulário controlado não contempla tão nível de especificidade.

Durante a indexação, o indexador da FSP explicita que a atribuição dos descritores na LILACS é pautada nos termos atribuídos durante a catalogação de assunto da mesma tese no DECS. Entretanto, é pertinente destacar que, de modo análogo, a catalogação de assunto em catálogos coletivos online deveria alcançar o mesmo nível de especificidade da indexação em bases de dados, ou seja, que os assuntos realmente representem o conteúdo dos documentos do tipo tese.

Para tanto, a linguagem documental tem um relevante papel, pois de nada vale o profissional realizar uma concepção de análise pautada no conteúdo documental se a linguagem documental utilizada (o vocabulário controlado) não acompanhar tal nível de especificidade. Desse modo, a constante atualização da linguagem com a participação de bibliotecários, dirigentes, especialistas e usuários permite maior qualidade na etapa de representação/tradução de conceitos durante o processo de catalogação de assunto tanto de teses como de livros no contexto das bibliotecas universitárias - elemento importante da política de indexação. A política de indexação refere-se à forma de realizar a indexação de uma determinada instituição para concretizar, sistematizar e reunir em manuais os processos da indexação, isto é, um guia para tomada de decisões (Gil Leiva, 2008; Carneiro, 1985). Esta reunião dos procedimentos em manuais está diretamente relacionada com o número de profissionais que se dedicam a esta atividade de indexação e ao nível de qualidade que o sistema de informação pretende alcançar.

Cada biblioteca universitária dispõe de elementos de política de indexação onde a interação destes visa, por meio de seus produtos e serviços, à efetiva recuperação da informação por seus usuários, pois cada instituição se beneficia de uma estrutura específica e de uma forma singular de atuar, considerando-se suas próprias especificidades e características. Nesse sentido, pressupõe-se que a atuação profissional do bibliotecário do tratamento temático da informação ocorra de maneira diferente em cada sistema de recuperação da informação, considerando-se que a atividade é influenciada direta ou indiretamente pela política de indexação adotada. Assim, torna-se necessário que a política de indexação em bibliotecas universitárias esteja descrita de maneira clara, objetiva e ao alcance de todos os atores que contribuem para o desenvolvimento desse processo dentro do sistema de informação - inclusive os próprios usuários.

\section{Quantidade de termos}

aí o que que eu faço? Nossa, só <Materiais dentários>? Aí eu vou colocar outro assunto ... vamos ver (C-FO)

Outra questão relevante, referente à quantidade de termos, é explicitada também pelo catalogador da FO, que explica que a quantidade limite de termos dos assuntos no registro do ALEPH é de no máximo 5 termos, o que denota este aspecto da política de indexação do sistema de recuperação da informação. Por outro lado, para o indexador da mesma instituição, quanto mais termos forem indexados, melhor para o pesquisador, proporcionando maior possibilidade de recuperação do documento. No entanto, em outro trecho, o profissional sinaliza que a política de indexação aponta quatro termos, para a representação dos assuntos contidos no material do tipo tese. Caso não seja possível este número de termos, três assuntos são aceitáveis, independentemente de se tratar de descritores primários ou descritores secundários.

Outro ponto a ser destacado é que o indexador da FSP explicita a quantidade limite de qualificadores iguais, sendo até três, durante a atribuição dos descritores na indexação.

O processo de indexação de materiais na LILACS pauta-se no Manual de Indexação de Documentos, que descreve os procedimentos que deverão ser seguidos para a análise do conteúdo de documentos a serem incorporados na mesma. 
Observa-se a inexistência de um manual na instituição que norteie a catalogação de assunto no DEDALUS, explicando, assim, a ausência desta temática nos protocolos verbais individuais dos catalogadores.

Desse modo, apreende-se a necessidade de uma política de indexação formalizada em um manual de indexação, que deve ser um instrumento real de trabalho e norteador dos princípios do processo de tratamento documental pela biblioteca universitária, a fim de que seja garantida a consistência tanto na catalogação de assunto como na indexação.

\subsubsection{Eixo temático: O usuário do sistema de recuperação da informação}

Recuperação por assunto em catálogo coletivo online e em bases de dados na biblioteca

então é sempre assim, alguém vai procurar direto essa ... <Compósitos dentários>, vai achar essa tese, mas ele também pode procurar, ele quer saber quais são os <Materiais dentários pra restauração>, aí nesse, ele pode achar esse <Compósitos> (CFO)

O catalogador da FO demonstra preocupação com a recuperação da tese pelo usuário, não apenas pelo assunto como por outros campos inseridos no registro do MARC.

\section{Preocupação com a perspectiva do usuário}

então eu sempre vejo outra perspectiva que o ... o usuário também pode estar procurando, né? (C-FO)

dar o link pro ... Currículo Lattes do autor é super importante, principalmente pra saber quais outros pesquisadores da minha própria Escola estão escrevendo e publicando sobre aquele assunto ... então ... é ... pra auxiliar até na rede de relacionamento que ele vai ter ... seja como psicólogo lá no futuro ou seja como pesquisador, mesmo, nato, né? (I-IP)

O mesmo profissional tenta prever a forma com que o usuário realizará a busca no sistema de recuperação da informação, proporcionando outros termos que o mesmo poderia utilizar para recuperar a tese. O catalogador reforça a categoria de recuperação por assunto, salientando que no campo 650 procura colocar os termos do ponto de vista de sua experiência profissional na área científica especializada, no caso, a Odontologia. Prioriza os termos em um nível de especificidade maior, ou seja, mais geral e menos específico, colocado pelo autor. O indexador do IP considera relevante a descrição do Currículo Lattes dos autores, auxiliando na recuperação dos mesmos.

Os usuários são um componente ativo e determinante no contexto de bibliotecas universitárias, pois são quem utilizam a informação. Enquanto os usuários reais referem-se a pessoas/instituições que fazem o uso efetivo dos recursos e serviços de uma unidade de informação, os usuários potenciais são vistos como aqueles que reúnem as características pelas quais foi elaborado o sistema de recuperação da informação, mas que por diferentes razões, não utilizam tais recursos. Assim, ao analisar um documento, o catalogador de assunto/ indexador não deve se limitar a representar ou resumir apenas a informação explícita nele contida, devendo ir além, indagando-se sobre as possibilidades de tornar o conteúdo do documento, ou parte dele, visível tanto para o usuário real como para o potencial.

De forma mais sistemática, verificou-se que algumas categorias propostas inicialmente para a análise dos protocolos não apareceram nas declarações dos sujeitos, o que denota que os protocolos verbais coletam uma parcela do processo em si, e não necessariamente todos os elementos que compõem a complexidade do processo de análise documental, materializado no processo de catalogação de assunto e de indexação no contexto das bibliotecas analisadas.

\section{Considerações finais}

A aplicação do PVI como metodologia qualitativa permitiu a observação comparativa dos processos de catalogação de assunto e de indexação realizados pelos profissionais em bibliotecas universitárias e do contexto de trabalho do catalogador e do indexador, levantando alguns pontos como as facilidades e dificuldades da realização dos processos em si.

Quanto ao catalogador de assunto/indexador, a questão da subjetividade, presente nas discussões da área e que acompanha o bibliotecário ao longo de sua trajetória profissional na determinação do(s) assunto(s), pode ser minimizada tanto pela realização de todas as etapas dos processos de catalogação de assunto/indexação como pela adoção de uma política de indexação bem definida em cada sistema de recuperação da informação, norteando sua atuação profissional.

Quanto aos processos de catalogação de assunto/indexação, verificou-se que o profissional realiza a catalogação de assunto e a indexação de forma distinta, visto que nas bases de dados o processo de indexação é realizado com mais especificidade do que na catalogação de assunto em catálogo coletivo online. Acredita-se que esta diferença esteja relacionada não apenas com o contexto de trabalho do bibliotecário, de um lado, em sua atuação como catalogador de assunto em catálogo coletivo online e, de outro, em sua atuação como indexador em base de dados de área 
científica especializada, mas também com os diferentes vocabulários controlados adotados. A atuação profissional é adaptada de acordo com cada tipo de sistema recuperação da informação, onde o principal diferencial reside no nível de especificidade alcançado pelo vocabulário controlado.

Enquanto no catálogo coletivo online utiliza-se um vocabulário mais geral que abarca diversos campos do conhecimento da Universidade, nas bases de dados o vocabulário é específico da área de Saúde, o que possibilita ao bibliotecário maior amplitude e possibilidade de escolha de determinados descritores para indexação de teses, embora nos dois sistemas de recuperação da informação exista a abertura para incorporação de novos termos aos vocabulários, de acordo com a demanda. Desse modo, cada vocabulário controlado - definido pela política de indexação de cada sistema de recuperação da informação reflete as características e a filosofia de cada contexto. O vocabulário controlado adotado pelo sistema de recuperação da informação é um instrumento da política de indexação que visa à recuperação da informação documental. Como elemento mediador entre a linguagem do conteúdo do documento e a linguagem do usuário do sistema de recuperação da informação, o vocabulário controlado tem papel fundamental tanto em catálogos coletivos online como em bases de dados. Assim, ressalta-se a necessidade de elaboração/atualização de um vocabulário controlado próprio para cada contexto, conferindo maior credibilidade da representatividade e a visibilidade em bibliotecas universitárias.

Em relação ao contexto do processo de catalogação de assunto/indexação, recomenda-se a necessidade de uma política de indexação formalizada em um manual de indexação que norteie a catalogação de assunto no catálogo coletivo online e a indexação em bases de dados científicas especializadas, cujos registros são inseridos pelos profissionais que neles atuam. $O$ estabelecimento de uma política de indexação do tratamento documental pressupõe maior qualidade da informação recuperada, pois as diretrizes e procedimentos de catalogação de assunto/indexação bem estabelecidos e seguidos pelos profissionais podem contribuir para uma maior consistência nos resultados da indexação.

\section{Notas}

(1) O DEDALUS é o catálogo coletivo online do Sistema de Bibliotecas da Universidade de São Paulo (SibiUSP), tendo o VocaUSP (Vocabulário Controlado da USP) como linguagem de representação temática.
(2) A base de dados LILACS (Literatura Latino-americana e do Caribe em Ciências da Saúde), criada em 1985 constitui atualmente o principal índice e repositório da produção científica e técnica em saúde nos países da América Latina e Caribe. Coordenada em âmbito regional pela BIREME/OPAS/OMS, é resultado de um esforço cooperativo de centenas de Centros Cooperantes de 37 países da América Latina e Caribe. Complementa índices internacionais, como MEDLINE e Web of Science e está disponível em três idiomas: português, espanhol e inglês.

(3) O CRUESP/BIBLIOTECAS iniciou suas atividades em 1999, como Grupo de Estudos instituído pela Resolução do Conselho de Reitores das Universidades Estaduais Paulistas (CRUESP) 149/99, tendo por objetivo a integração dos Sistemas de Bibliotecas da Universidade de São Paulo (USP), Universidade Estadual Paulista (UNESP) e Universidade Estadual de Campinas (UNICAMP) do Brasil.

\section{Annexes in a separate file I Apéndices en un fichero adjunto}

\section{Referências}

Carneiro, M. V. (1985). Diretrizes para uma política de indexação. // Revista da Escola de Biblioteconomia da UFMG. 14: 2 (set. 1985) 221-241.

Cavalcanti, M. C. (1989). I-n-t-e-r-a-ç-ã-o leitor-texto: aspectos de interpretação pragmática. // Campinas: UNICAMP, 1989.

Ericsson, K. A.; Simon, H. A. (1993). Protocol analysis: verbal reports as data. // Cambridge: MIT Press, 1993.

Fiuza, M. M. (1985). O ensino da catalogação de assunto. // Revista da Escola de Biblioteconomia da UFMG. 14:2 (set. 1985) 257-269.

Fujita, M. S. L.; Rubi, M. P.; Boccato, V. R. C. (2009). As diferentes perspectivas teóricas e metodológicas sobre indexação e catalogação de assuntos. // Fujita, M. S. L. (Org.). A indexação de livros: a percepção de catalogadores e usuários de bibliotecas universitárias. São Paulo: Cultura Acadêmica, 2009. 19-42.

Gil Leiva, I. (2008). Manual de indización: teoría y práctica. // Gijón: Trea, 2008.

Guinchat, C; Menou, M. (1994). Introdução geral às ciências e técnicas da informação e documentação. Brasília: IBICT, 1994. p. 133-165.

Nardi, M. I. A. (1999). A metáfora e a prática de leitura como evento social: instrumentos do pensar a Biblioteconomia do futuro. $272 \mathrm{f}$. Tese (Doutorado em Linguística Aplicada e Estudos da Linguagem) - Pontifícia Universidade Católica, São Paulo.

Rasmussen, E. (2011). Library systems. // Baeza-Yates, R.; Ribeiro-Neto, B. Modern information retrieval: the concepts and technology behind search. 2. ed. Harlow: Addison Wesley, 2011.

Shoham. S.; Kedar, R. (2001). The subject cataloging of monographs with the use of keywords. // Cataloging \& Classification Quarterly. 33:2 (2001) 29-54.

Tartarotti, R. C. D. E. (2014). Atuação bibliotecária no tratamento temático da informação em unidades informacionais: um estudo comparativo qualitativo-quantitativo. // 277 f. Dissertação (Mestrado em Ciência, Tecnologia e Sociedade) - Universidade Federal de São Carlos.

Enviado: 2016-047-02. Segunda versión: 2016-07-11. Aceptado: 2017-09-13. 